\title{
Ultrasound Pretreatment of Apple Slice Prior to Vacuum Freeze Drying
}

\author{
Ziying Ren, Yaxiang Bai ${ }^{\text {a, * }}$ \\ School of Science, Dalian Ocean University, Dalian, China. \\ *, a Byx0671@163.com
}

\begin{abstract}
To improve the vacuum freeze drying rate and to reduce the energy consumption of apple slice, apple slice were treated with different ultrasonic frequency, time and temperature. The vacuum freeze drying rate of treated apple slice was determined and, meanwhile, the rehydration ratio of samples with pre-treatment were determined to compare with those of untreated samples. The results indicated that ultrasonic pre-treatment can significantly improve the drying rate of apple slice, and increase the rehydration rate of the dried apple slice. Under a $100 \mathrm{kHz}$ for 5 min at $25^{\circ} \mathrm{C}$, the drying rate of pre-treatments is 1.25 times higher compared with that of the control group.
\end{abstract}

Keywords: Vacuum freeze; Apple slice; Drying rate.

\section{Introduction}

Fruits and vegetables are important sources of essential dietary nutrients such as vitamins, minerals and fi bra. Since the moisture content of fresh fruits and vegetables have a moisture content ranging from $75 \%$ to $90 \%$. They are highly heat sensitive and are apt to be highly perishable. Drying is defined as the reduction of moisture from the products and is an efficient and cheap method for the preservation of fruits and vegetables [1-3]. Hot air drying is one of the most commonly used procedures in dried fruits and vegetables, with main disadvantages yielding low rehydration rate and low nutritive value, etc. [4-6]. Compared with other drying methods, vacuum freeze-drying is the best way to maintain the quality of food [7-8]. Based on the sublimation of the frozen products to achieve the purpose of dehydration freeze-drying, because no liquid water in the drying process, the moisture in the solid state and in situ sublimation, in low temperature, hypoxia, stagnation of most biological reactions, so that the original structure and shape of the material by minimal damage, so as to obtain high quality products [9].Therefore vacuum freeze-drying technology possesses the advantage of minimal deterioration of original color, flavor, texture, or nutritional values[10]. However, the technique hasn't been popular, mainly because of long drying time and high energy consumption [11]. Therefore it is necessary to explore low power consumption processing for vacuum freeze-drying.

An approach to increase energy efficiency is to find a proper pretreatment method. Many agricultural products are subjected to a particular pretreatment to improve drying characteristics and consequently shorten drying time [12].Such pretreatments include alkaline dips, freezing, sulfiting,or blanching. However, pretreatment with chemicals decreases color and flavor quality, and thermal pretreatment is responsible for undesirable changes in quality attributes of fruit tissue.

Ultrasound pretreatment is a promising food processing technology due to its continuous application with very little heating of the medium, short treatment time, low energy requirement. Studies in recent years have demonstrated that as a pre-processing step for fruits and vegetables in the drying process, ultrasound pretreatment is able to cause reversible membrane perforation, and it is hoped that it will help to increase dryer efficiency, save energy, and enhance product quality [1315].

At present, there are only few reports on vacuum freeze drying fruits and vegetables products using ultrasound pretreatment. In this paper, apple slices, were treated in an ultrasound system, in different frequency, time and different temperature. The vacuum freeze drying rate of treated apple slices was determined and, meanwhile, the rehydration rate of samples with pretreatment were determined to compare with those of untreated samples. 


\section{Experimental Procedure}

All manuscripts must be in English, also the table and figure texts, otherwise we cannot publish your paper. Please keep a second copy of your manuscript in your office.

When receiving the paper, we assume that the corresponding authors grant us the copyright to use the paper for the book or journal in question. Should authors use tables or figures from other Publications, they must ask the corresponding publishers to grant them the right to publish this material in their paper.

\subsection{Experimental Equipment}

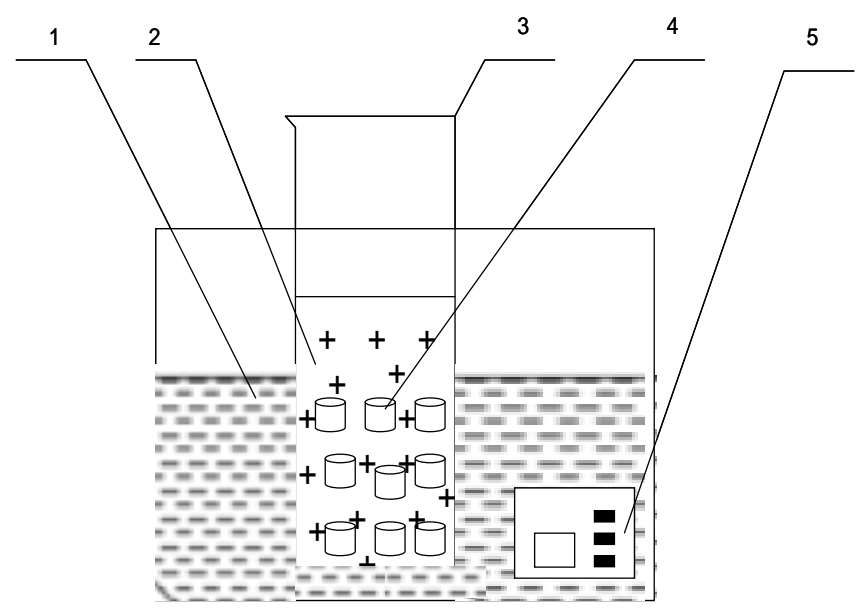

1. Constant temperature water bath 2. Water 3. Beaker 4. Samples 5. Ultrasonic generator

Figure 1. Schematic of the Ultrasound Pretreatment System

Figure 1 shows a schematic diagram of ultrasound pretreatment system setup developed for the experimental work. Its main components are an ultrasonic generator and a constant temperature water bath. The range of frequency of which can be adjusted from 50 to $100 \mathrm{kHz}$ by a controller.

\subsection{Experimental Methods}

The apple slices were divided into 31 groups with similar weights. One was the control group and the others were experimental groups. The experimental groups were subjected to ultrasonic generator with different temperature $\left(15,25^{\circ} \mathrm{C}\right)$, different frequency $(50,60,80,90,100 \mathrm{kHz})$ and different time (5, 10, $15 \mathrm{~min})$, respectively. Then, all samples were dried by vacuum freeze until they reached the final moisture content $(10 \pm 1 \%)$.

\subsection{Average Drying Rate Measurement}

The samples of the apple slices in the control group and the samples of the apple slices after the ultrasonic pretreatment were put into the vacuum freeze drying machine for drying. And then, to record the data, we can calculate the average drying rate $(\mathrm{g} / \mathrm{h})$ of the apple slices through the data.

$$
\text { Percentage shrinkage }=\left(Z_{0}-Z_{f}\right) Z_{0}^{-1} \times 100
$$

Where Z0 (g) and Ziff (g) are the quality of each group of apple slices at the beginning and at the end of each drying experiment, respectively.

\subsection{Water Absorption and Rehydration Rate Measurement}

Rehydration ratio was determined by soaking dried apple slices in hot water at $100^{\circ} \mathrm{C}$. The soaked apple slices were blotted with a paper towel of good quality to remove excess water. They were then 
weighed and placed back into the soaking water. Rehydration ratio value was expressed in percentage and calculated as mass of water absorbed per $100 \mathrm{~g}$ of dried apple slices using the following formula.

$$
\text { Percentage rehydration ratio }=\left(m_{g}-m_{0}\right) m_{0}^{-1} \times 100
$$

Where $\mathrm{m} 0$ (g) and $\mathrm{mg}(\mathrm{g})$ are weights of the samples before and after rehydration, respectively.

\section{Results and Analysis}

\subsection{Effects of Ultrasound Pre-Treatment on Vacuum Freeze Drying Apple Slice for Drying Rate}

The influence of ultrasound pretreatment on average drying rate was shown in Figure 2-4, respectively. It can be seen from the graphs that the average drying rate of ultrasonic pretreatment apple slice was higher than that of the control. Under a $100 \mathrm{kHz}$ for $5 \mathrm{~min}$ at $25^{\circ} \mathrm{C}$, the average drying rate of pretreatments is 1.25 times higher compared with that of the control group. The reason why ultrasound can improve the vacuum freeze drying rate may be ultrasound can destroy the cell membrane of the sample, thus enhancing the permeability of the cell membrane, the water in the cell more easily exudate from the cell, and then improve the drying rate of materials.

\subsection{Effects of Ultrasound Pretreatment on Vacuum Freeze Drying Apple Slice for Rehydration Rate Measurement}

The influence of ultrasonic pretreatment on rehydration rate of apple slice was shown in Figure 57 , respectively. We found that ultrasonic pretreatment could increase the rehydration rate of apple slice.

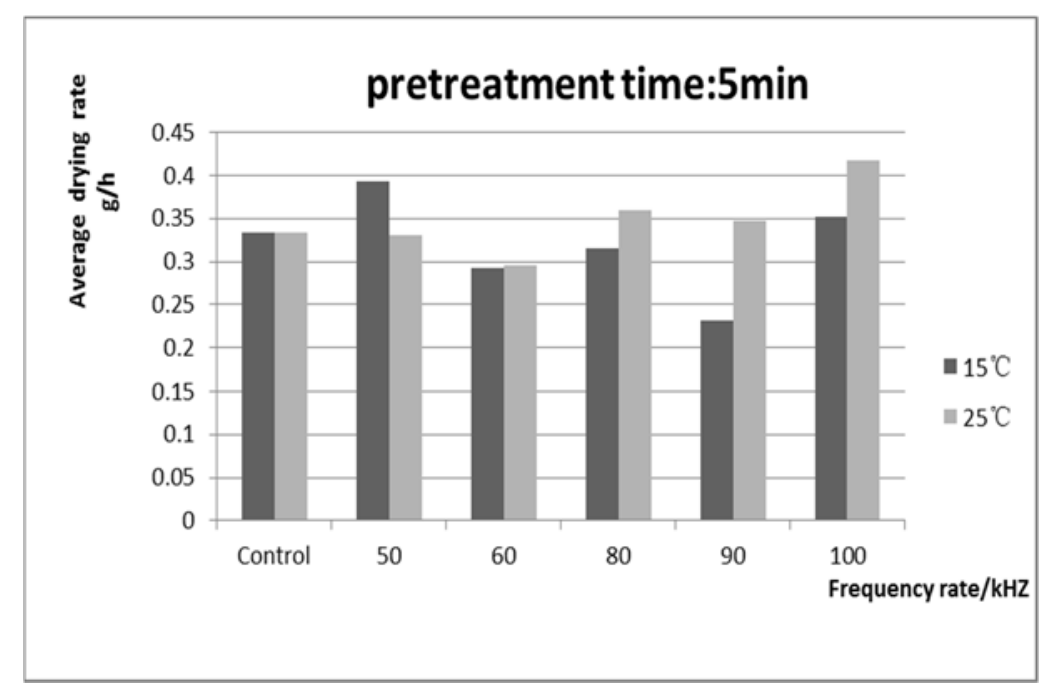

Figure 2. Effect of Ultrasonic Pretreatment on Average Drying Rate of Vacuum Freeze Drying Apple Slice 


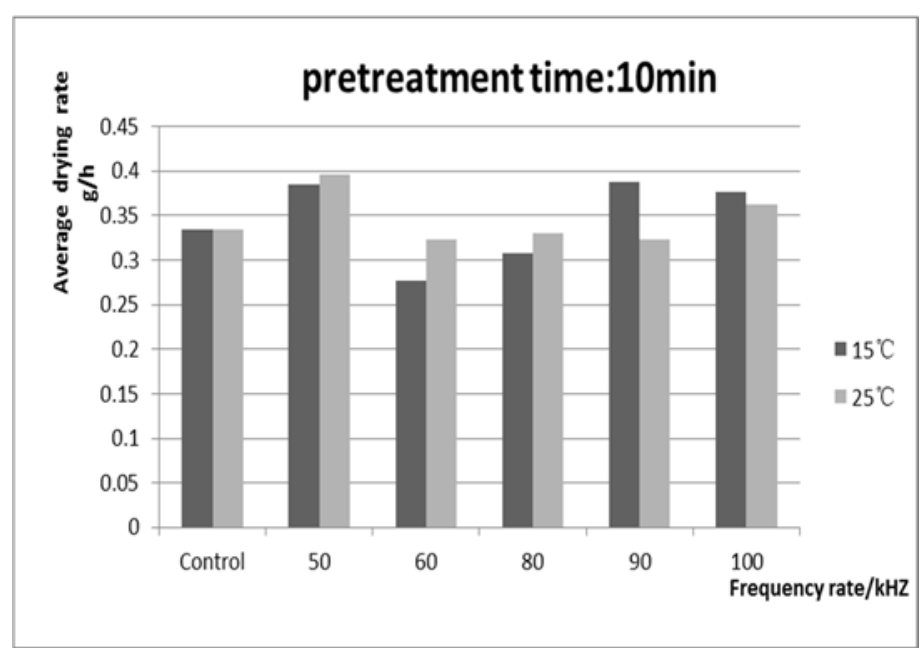

Figure 3. Effect of Ultrasonic Pretreatment on Average Drying Rate of Vacuum Freeze Drying Apple Slice

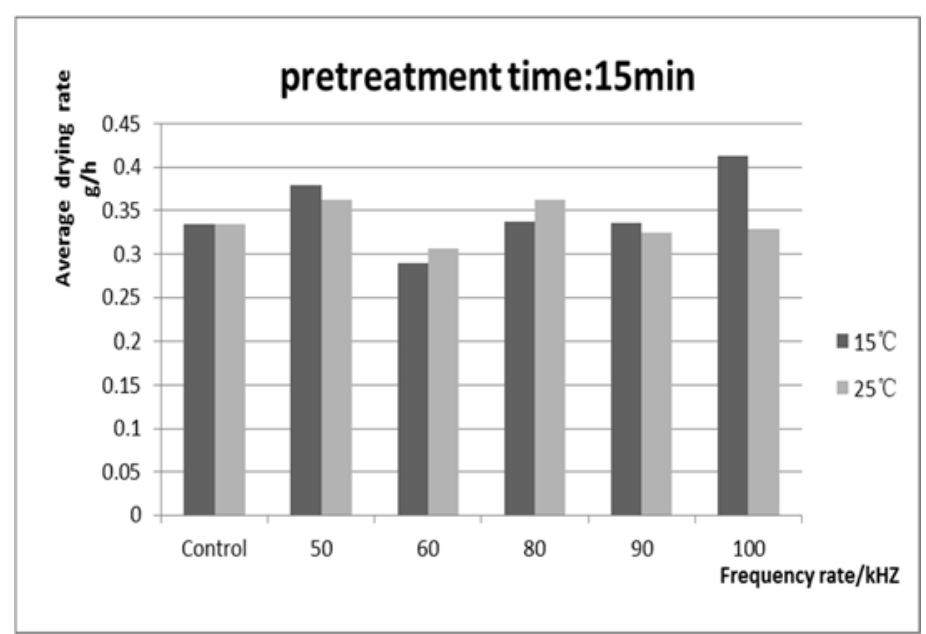

Figure 4. Effect of Ultrasonic Pretreatment on Average Drying Rate of Vacuum Freeze Drying Apple Slice

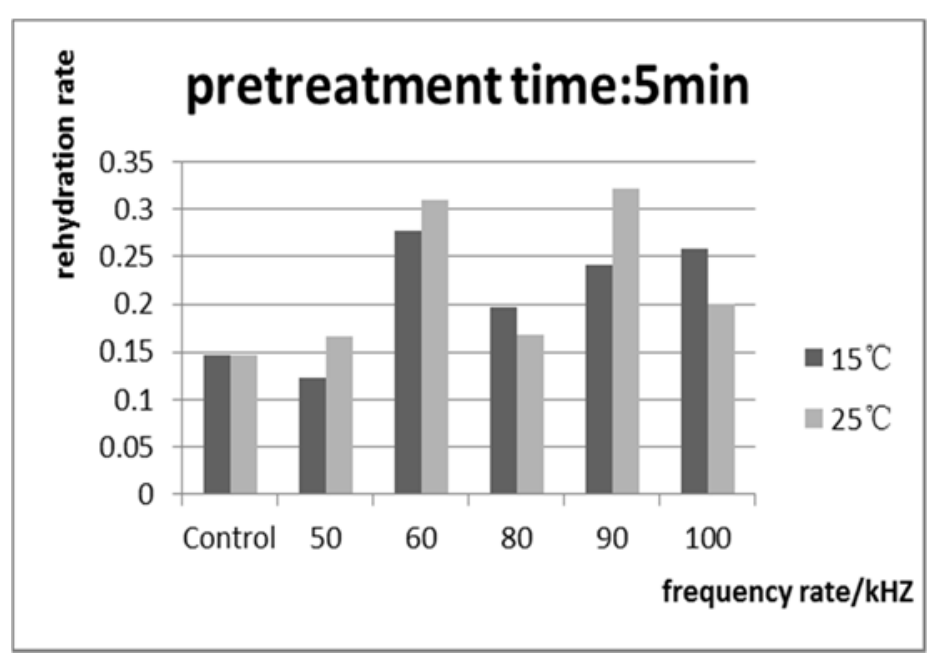

Figure 5. Effect of Ultrasonic Pretreatment on Average Drying Rate of Vacuum Freeze Drying Apple Slice 


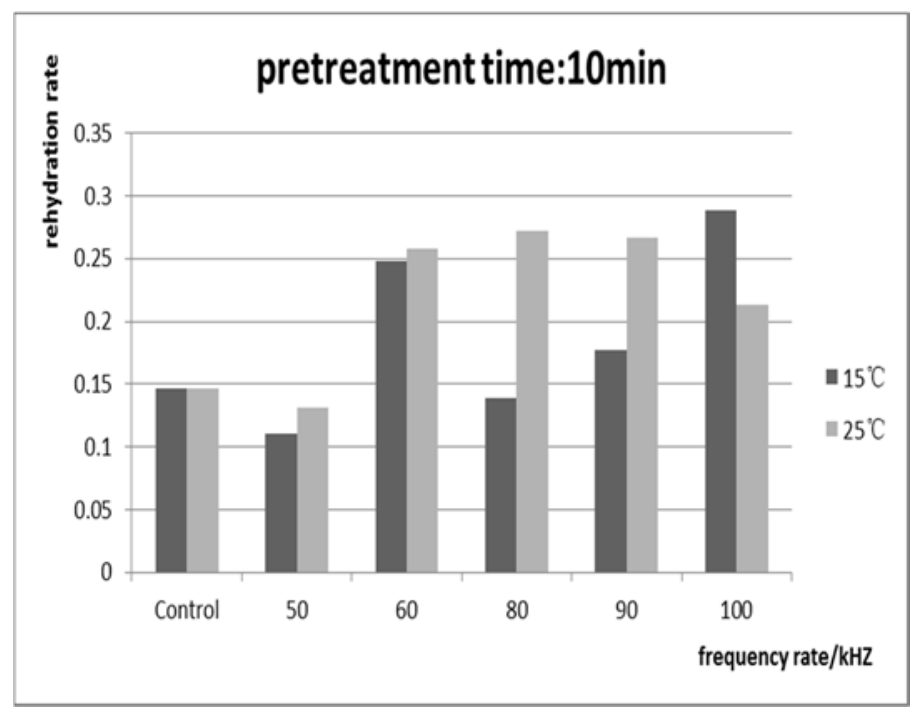

Figure 6. Effect of Ultrasonic Pretreatment on Average Drying Rate of Vacuum Freeze Drying Apple Slice

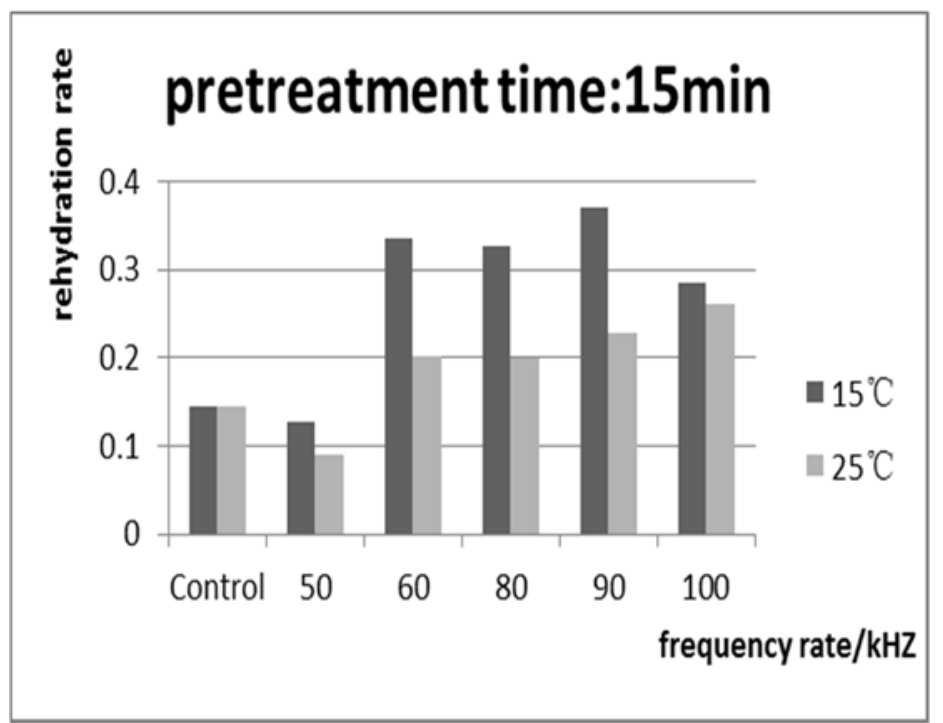

Figure 7. Effect of Ultrasonic Pretreatment on Average Drying Rate of Vacuum Freeze Drying Apple Slice

\section{Conclusion}

In this study, apple slice was pretreated in an ultrasonic system prior to vacuum freeze drying, and, the drying rate, the effects of ultrasonic pretreatment on apple slice's rehydration ratio were investigated and compared with control group. The results can be summarized as follows:

The drying rate of apple slice can be improved by ultrasonic pretreatment, and while ultrasonic pretreatment was applied by $100 \mathrm{kHz}$ for $5 \mathrm{~min}$ at $25^{\circ} \mathrm{C}$, the drying rate could be increased approximately $25 \%$. And, ultrasonic pretreatment can improve the rehydration rate of dried apple slice.

\section{Acknowledgments}

This work was supported by the Scientific Research Fund of Liaoning Provincial Education Department under contract No (L2013273). 


\section{References}

[1]. E. Amami, L. Khezami, E. Vorobiev, N. Kechaou, Effect of pulsed electric field and osmotic dehydration pretreatment on the convective drying of carrot tissue, Drying Technol. 26 (2008) 231-238.

[2]. Y.L. Wu, Y.M. Guo, D.G. Zhang, Study of the Effect of High-Pulsed Electric Field Treatment on Vacuum Freeze-Drying of Apples, Drying Technol. 29 (2011) 1714-1720.

[3]. B.I.O Ade-Omowaye. N.K Rastogi. A. Angersbach. D. Knorr, Osmotic dehydration of bell peppers: influence of high intensity electric field pulses and elevated temperature treatment, J. Food Eng. 54 (2002) 35-43

[4]. C. Ratti, Hot air and freeze-drying of high-value foods: a review, J. Food Eng. 49 (2001), 311319.

[5]. V. R.Sagar, P. Suresh Kumar, Recent advances in drying and dehydration of fruits and vegetables: a review, J Food Sci Techno. 47 (2010) 15-26.

[6]. G. Barbara, Dehydrated Goods, Food Manu. 73(1998) 30-31.

[7]. V. Sapru, T.P Labuza. Glass state in bacterial spores predicted by polymer glass-transition theory. Food Sci. 58 (1993) 445-448.

[8]. Z. Irzyniec. J. Klimezak. S. Michalowski, Freeze-drying of the black currant juice. Drying Technol. 13 (1995) 417-424.

[9]. E. A Boss. R.M Filho. E. Coselli, Freeze drying process: real time model and optimization, Chem Eng Process. 43 (2004) 1475-1485.

[10]. X. Fang,X. Zhang,J. Wang,Q. Zhang,H. Xiao,Y. Liu,H. Ju,S. Liang,Z. Gao, Vacuum pulsed drying characteristics and quality of lotus pollen,Trans. CSAE. 32 (2016) 287-295.

[11]. Y.Y. Xu, M. Zhang, A.S. Mujumdar, X. Duan, J.C. Sun, A two-stage vacuum freeze and convective air drying method for strawberries, Drying Technol. 24 (2006), 1019-1023.

[12]. Y.C. Won, S.C. Min, D.U. Lee, Accelerated Drying and Improved Color Properties of Red Pepper by Pretreatment of Pulsed Electric Fields, Drying Technol. 33 (2015) 926-932.

[13]. D. Yun, Y.Y. Zhao, Effects of pulsed-vacuum and ultrasound on the osmodehydration kinetics and microstructure of apples (Fuji), J. Food Eng. 85 (2008) 84-93.

[14]. A.N. Fabiano, L.F. Fernandes, S. Rodrigues, Ultrasound as pre-treatment for drying of pineapple, Ultrasonic Sonochemistry, 15 (2008) 1049-1054.

[15]. K. Schossler, H. Jaeger, D. Knorr, Novel contact ultrasound system for the accelerated freeze-drying of vegetables, Innov Food Sci Emerg. 16 (2012) 113-120. 